\title{
Viga vagão com seção transversal retangular de madeira reforçada com barra de aço
}

\author{
Queen-post truss consisting of a rectangular timber \\ cross section reinforced with steel bar
}

\begin{abstract}
Thais Alves Cunha
Francisco Antonio Romero Gesualdo

Resumo

$\mathbf{O}$

sistema chamado de viga vagão formado por uma viga principal, um ou dois montantes e tirantes fixados nas extremidades da peça, resulta em um modelo estrutural leve, de fácil manuseio, boa rigidez e de boa capacidade mecânica. Além de avaliar a eficiência do sistema em relação à uma viga simples, também foi realizada a análise entre os resultados experimentais e os gerados por dois métodos de cálculo distintos. Nos três casos foi possível concluir que o sistema de viga vagão produz grande eficiência, pois para vigas de Angelim Vermelho (Dinizia excelsa Ducke) tem-se um ganho de rigidez médio de $623 \%$, e para as peças de tábuas de Pinus tem-se $518 \%$ de ganho de rigidez.

Palavras-chaves: Viga vagão. Viga armada. Madeira reforçada com aço. Viga reforçada.

Thais Alves Cunha Ayres de Lima Alves Ltda. Uberlandia - MG - Brasil

Francisco Antonio Romero Gesualdo Universidade Federal de Uberlândia Uberlandia - MG - Brasil

Recebido em 02/06/14 Aceito em 05/10/15

\section{Abstract}

The systems called king and queen post trusses are formed by a main wood member, one or two vertical wood posts and tied by steel bar. These systems result in a lightweight structural model, offering easy handling, good rigidity and mechanical capacity. As well as evaluating the system's efficiency compared to a simple beam, this study analyses the experimental results and those generated by two different methods of calculation. In all three cases it was concluded that the afore mentioned system produces high efficiency, since the Red Angelim (Dinizia excelsa Ducke) beams presented an average stiffness gain of 623\%, and the Pinus boards and parts presented a $518 \%$ stiffness gain.

Keywords: King and queen-post truss. Inverted truss. Timber and steel. Reinforced beam.
\end{abstract}




\section{Introdução}

O sistema conhecido no Brasil como viga vagão é aqui objeto de estudo visando alcançar novo sistema de montagem, que, além de aumentar resistência, possa agilizar e facilitar seu uso na construção civil. Consiste em peças retangulares de madeira, associadas a um ou dois montantes vinculados a cabos de aço (Figura 1). O estudo do sistema viga vagão se justifica pela necessidade de um arranjo estrutural leve, resistente e rígido para aplicação na construção civil.

Nesse conjunto estrutural a madeira aparece como o componente predominante, pois representa a viga principal e os montantes. Segundo Rebelo e Bogéa (2004), a própria viga é responsável por absorver todo o empuxo horizontal que o cabo aplica nos apoios, resultando apenas em forças verticais.

Embora seja um sistema pouco difundido na literatura, é de aplicação antiga, como em pontes ferroviárias, exposto por Jameson (1980), em que o arranjo estrutural consiste na parte superior do sistema trabalhando sob compressão, enquanto a parte inferior trabalha tracionada. Exemplos de aplicação podem ser encontrados em Herzog et al. (2004). Considerações sobre procedimentos de cálculo convencional são apresentadas em Faherty e Williamson (1999).

Rodrigues (2004) apresenta soluções para reforço em estrutura de madeira utilizando tirantes metálicos, e o mesmo autor ainda comenta sobre as dificuldades de ligação entre os materiais. Contudo, uma opção de fixação do tirante na viga principal foi estudada no trabalho de Gesualdo e Lima (2007), em que foi apresentado o sistema chamado de cabo enlaçado superiormente em peças roliças, no qual a ligação se dá com o auxílio de pinos transversais. Já em Gesualdo e Cunha (2009) tem-se a viga principal com seção dupla retangular de madeira e o tirante de cabo de aço, em que ficam ressaltadas algumas desvantagens quando se usam cabos de aço, tais como a necessidade de ajuste até a acomodação dela. Como alternativas para a substituição do cabo foram analisadas, experimental e numericamente, sistemas com barra de aço, de seção circular maciça.

Para a realização dos experimentos foram empregadas peças de madeira com seções transversais facilmente encontradas no mercado brasileiro, das espécies pínus e angelim vermelho.

Peças para as espécies de pínus, com seções transversais maciças mais robustas como $4,5 \mathrm{~cm} \times$ $13 \mathrm{~cm}$, são mais comuns em peças com comprimentos menores, assim foram montadas duas vigas de pínus com essas características e comprimento total de $210 \mathrm{~cm}$.

Como exposto em Gesualdo e Cunha (2009), a viga vagão tem seus efeitos favoráveis majorados com o aumento do vão livre. Sendo assim, também foram analisadas peças de pínus de comprimento igual a $290 \mathrm{~cm}$, contudo, como eram peças mais esbeltas, tábuas com seção transversal de medidas $2,0 \mathrm{~cm} \times 12 \mathrm{~cm}$, foram utilizadas duas peças justapostas, unidas com pregos apenas para facilitar a montagem do sistema.

Para a espécie de angelim vermelho é comum encontrar peças com comprimentos maiores, mantendo a robustez da seção transversal. Assim, foram ensaiadas vigas com as seguintes dimensões: $4,1 \mathrm{~cm} \times 9,2 \mathrm{~cm} \times 300 \mathrm{~cm}$.

$\mathrm{Na}$ Tabela 1 tem-se o resumo dos ensaios realizados.

\section{Análise experimental}

\section{Montagem do sistema}

Os ensaios foram realizados sob uma laje de reação de dimensões $300 \mathrm{~cm} \times 600 \mathrm{~cm} \times 60 \mathrm{~cm}$, do laboratório de Estruturas da Faculdade de Engenharia Civil da Universidade Federal de Uberlândia. Para aplicação da força foi utilizado um macaco hidráulico, fixado em um arranjo formado por um suporte transversal e quatro barras rosqueáveis afixadas na base da laje de reação.

A força aplicada foi medida através de uma célula de carga de $100 \mathrm{kN}$, e o deslocamento vertical do foi medido através de transdutores de deslocamentos com capacidade de $100 \mathrm{~mm}$. Foi empregado o sistema de aquisição de dados da marca HBM chamado Spider8. Portanto, todo o sistema de leitura de dados foi feito eletronicamente, havendo total concatenação temporal entre a leitura de forças e a dos deslocamentos.

Para a fixação da barra na viga principal de madeira foi necessário utilizar chapas de aço e parafusos a fim de interligar os elementos e formar um sistema monolítico. Para cada viga foram necessárias quatro chapas, uma em cada face e extremidade da viga, para receber a barra circular, fixada por soldagem com eletrodo revestido, conforme ilustrado na Figura 2.

Antes da montagem dos sistemas, foram realizadas análises numéricas empregando-se o programa computacional Ansys $^{\circledR}$ (ANSYS, 2010), para identificar a variação do comportamento da viga 
vagão quando da variação da espessura e do posicionamento da chapa na viga de madeira. Assim, ainda na Figura 2a tem-se a representação dos fatores analisados como a espessura da chapa, a distância do centro da chapa até a face inferior da viga (hc) e, horizontalmente, do centro do apoio até o centro da chapa (cv).

Além do comprimento da viga e do posicionamento da chapa, existem outros fatores que influenciam na eficiência do sistema, como exposto em Morais e Gesualdo (2008). Assim,

Figura 1 - Esquema do sistema viga vagão

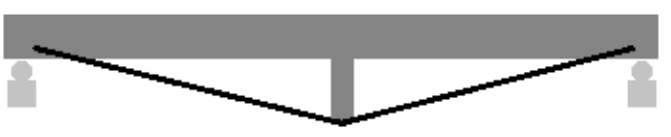

(a) Viga vagão com um montante foram colocados dois montantes em cada viga, os quais tiveram seus comprimentos e posições previamente calculados, além de terem sido verificados os parâmetros $d x$ e $d y$, que são as distâncias ideais entre os parafusos $e x$ e $e y$, que são as distâncias do centro do parafuso às extremidades horizontal e vertical da chapa.

Nos ensaios foram empregadas, para cada viga, duas barras de aço CA 50 com diâmetro de $6,3 \mathrm{~mm}$ e quatro chapas de dimensões $5 \mathrm{~cm} \times 10 \mathrm{~cm}$, com $3 \mathrm{~mm}$ de espessura (1/8").

Tabela 1 - Descrição dos grupos de ensaios

\begin{tabular}{|c|c|c|c|}
\hline Viga & Madeira & $\begin{array}{c}\text { Seção transversal } \\
(\mathrm{cm} \times \mathrm{cm})\end{array}$ & $\begin{array}{c}\text { Comprimento bruto } \\
(\mathrm{cm})\end{array}$ \\
\hline V1 a V4 & Pínus & $4,0 \times 12,0$ & 300 \\
\hline V5 e V6 & Pínus & $4,5 \times 13,0$ & 210 \\
\hline V7 e V8 & Angelim vermelho & $4,1 \times 9,2$ & 300 \\
\hline
\end{tabular}

Figura 2 - Detalhes da montagem do sistema viga vagão

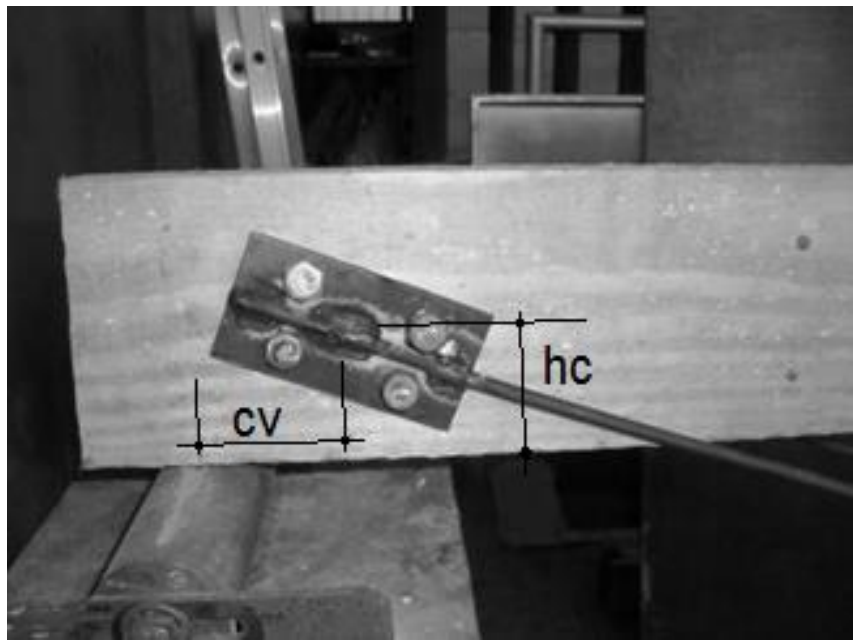

(a) Fixação da barra na chapa e da chapa na viga

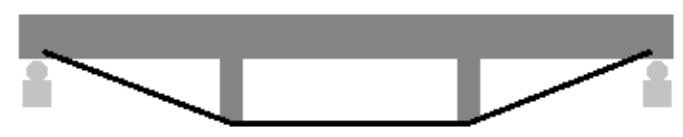

(b) Viga vagão com dois montantes 


\section{Resultados}

\section{Viga V1}

A viga V1, formada por tábuas de pínus, com seção transversal de $12,0 \mathrm{~cm} \times 4,2 \mathrm{~cm}$ e vão livre de $290 \mathrm{~cm}$, foi primeiramente ensaiada como viga simples, sem a barra (para caracterização do material e fornecimento de dados para comparação). Antes de atingir uma força de $5 \mathrm{kN} \mathrm{o}$ ensaio foi paralisado, montou-se a viga vagão e iniciou-se nova etapa de carregamento. Partindo de uma força nula, o sistema foi carregado até o limite de $19,38 \mathrm{kN}$, instante em que uma das tábuas se rompeu. Foi possível notar que durante o ensaio a viga flambou, assumindo a configuração de um "S" (Figura 3a).

Também foi notório o rompimento ocorrido no montante. A barra de aço, que trabalha como um tirante no sistema, transmite parte dos esforços absorvidos à viga, como força normal. A instabilidade lateral da viga pode ser resultado

\section{Figura 3 - Detalhes do ensaio da viga V1}

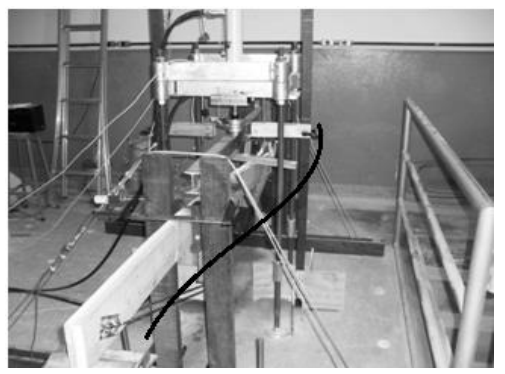

(a) Viga no momento da ruptura, deformada lateralmente dessa força de compressão associada à flexão da viga.

$\mathrm{Na}$ Figura 4 tem-se a representação do comportamento das tábuas de pínus trabalhando como estrutura simples e como viga vagão.

\section{Viga V2}

A viga $\mathrm{V} 2$, de seção transversal de 12,0 $\mathrm{cm} \times 3,8$ $\mathrm{cm}$, foi ensaiada como simples e, posteriormente, com a barra de aço. Durante o ensaio a viga permaneceu aprumada, porém, com a força próximo de $21 \mathrm{kN}$, o perfil metálico utilizado para distribuir a força aplicada pelo macaco hidráulico sofreu um tombamento, o que impossibilitou o registro da força máxima na ruptura. Pelo gráfico da Figura 5 é possível observar o comportamento dos sistemas e a discrepância no deslocamento vertical registrado.

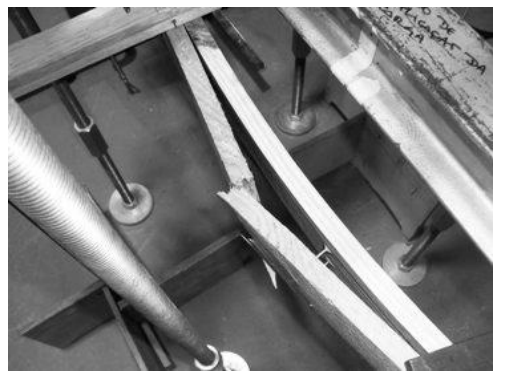

(b) Vista superior do ponto de ruptura

Figura 4 - Ensaio da viga V1

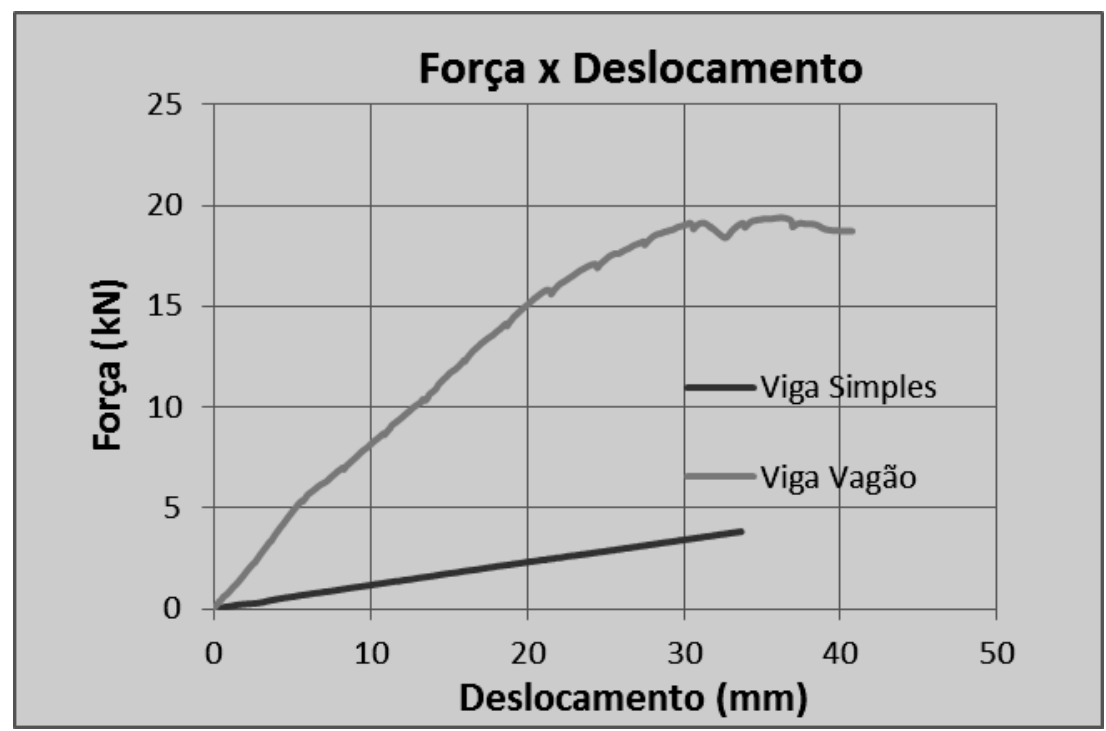

232 Cunha, T. A.; Gesualdo, F. A. R. 
Figura 5 - Ensaio da viga V2

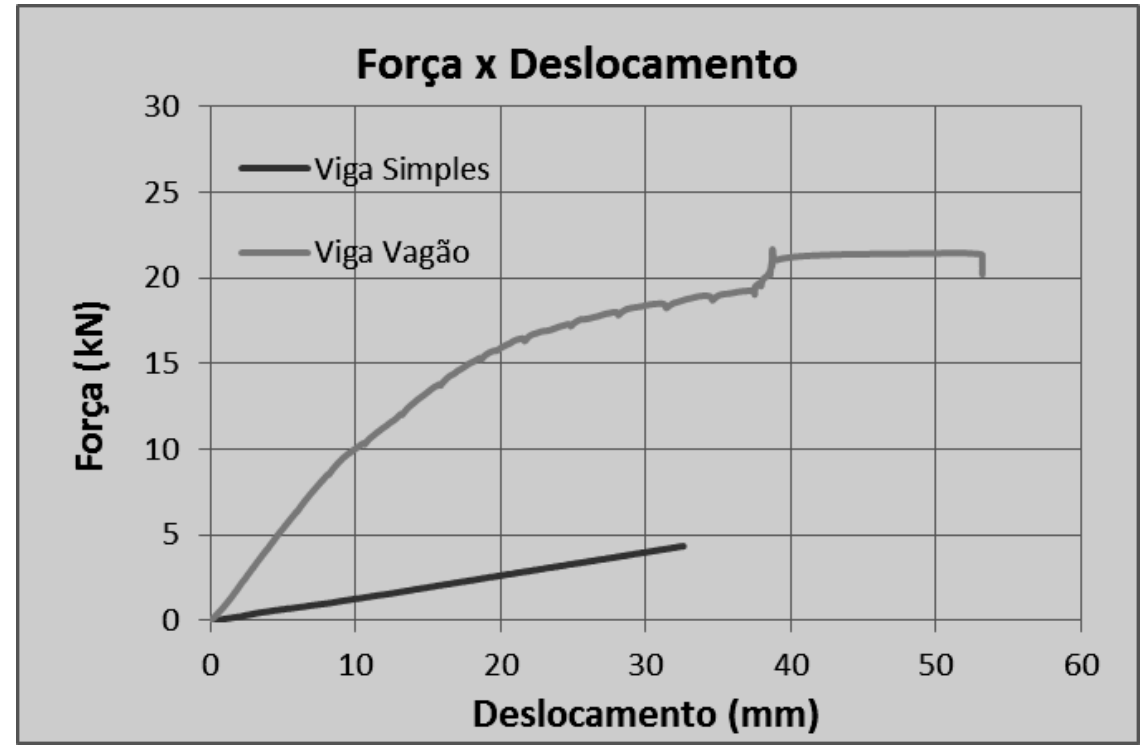

\section{Viga V3}

A viga $\mathrm{V} 3$ possuía seção transversal de $12,0 \mathrm{~cm} \times$ $4,0 \mathrm{~cm}$. Durante a realização do ensaio houve a mesma instabilidade lateral ocorrida nas demais vigas com tábuas de pínus, fazendo com que durante o ensaio a V3 assumisse a configuração de "S". O ensaio foi paralisado devido ao tombamento do perfil metálico.

Como o aço havia-se deformado, foram retiradas as barras e feito um ensaio com viga simples de seção transversal dupla até atingir a ruptura. $O$ comportamento do sistema é mostrado na Figura 6.

\section{Viga V4}

Com seção transversal de $11,9 \mathrm{~cm} \times 4,2 \mathrm{~cm}$, a viga V4 teve seu ensaio semelhante aos demais para as vigas formadas por tábuas de pínus. Quando atingiu a ruptura, verificou-se que a viga havia perdido a estabilidade lateral. $\mathrm{O}$ sistema atingiu a ruptura para uma força de $23,58 \mathrm{kN}$, com rompimento de uma das tábuas, conforme ilustrado na Figura 7.

\section{Viga V5}

As vigas V5 e V6 foram montadas com peças serradas de pínus, com seção retangular de $13 \mathrm{~cm}$ $\times 4,5 \mathrm{~cm}$. O sistema foi montado para a viga com $200 \mathrm{~cm}$ de vão livre, ou seja, 30\% menor que as demais vigas.

A ruptura do sistema viga vagão (V5) se deu no centro da viga, para uma força de $34,3 \mathrm{kN}$. Após a paralisação do ensaio foi possível notar a grande deformação da peça de madeira na região do apoio, ocorrida pela compressão normal às fibras da madeira, o que pode ser amenizado utilizandose uma chapa de distribuição de tensões sobre o apoio. Acredita-se que esse esmagamento não tenha prejudicado o resultado do ensaio, pois a concentração de tensões atingiu apenas o entorno do apoio, próximo da extremidade da viga. Assim, os dados deste ensaio foram considerados na análise de resultados e estão representados na Figura 8.

\section{Viga V6}

A viga V6 foi ensaiada primeiramente como viga simples. Foi observada a região de apoio da viga, mas ela não estava afetada, por se tratar da aplicação de uma força consideravelmente menor. No segundo ensaio, feito com a barra de aço fixada, foi possível notar abaulamento da peça nas regiões em contato com o aparelho de apoio, de forma semelhante ao ocorrido com a viga V5. O gráfico da Figura 9 exibe os resultados dos ensaios. $\mathrm{O}$ sistema teve uma ruptura localizada no apoio do lado direito, para uma força de $29,71 \mathrm{kN}$. Pela Figura 9a nota-se que no momento de soldar a barra de aço na chapa houve um aquecimento excessivo, que causou a carbonização superficial da madeira. Após a ruptura foi possível observar que a profundidade da carbonização, em algumas regiões, chegou a $0,3 \mathrm{~cm}$. 
Figura 6 - Ensaio da viga V3

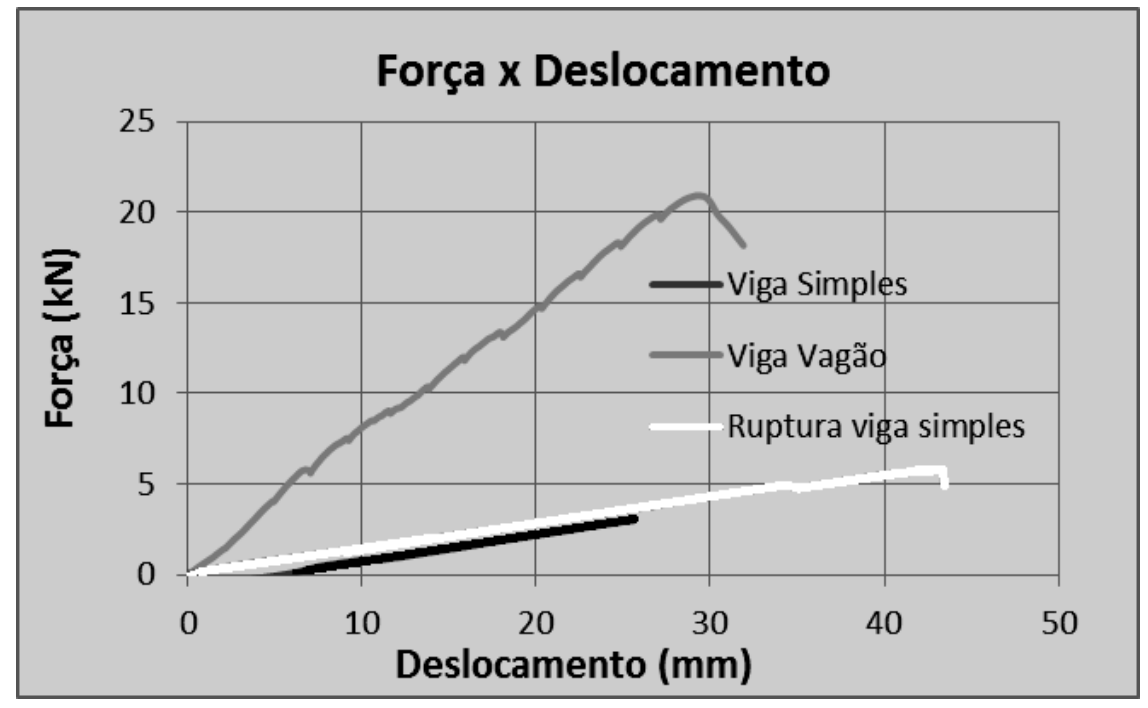

Figura 7 - Ensaio da viga V4

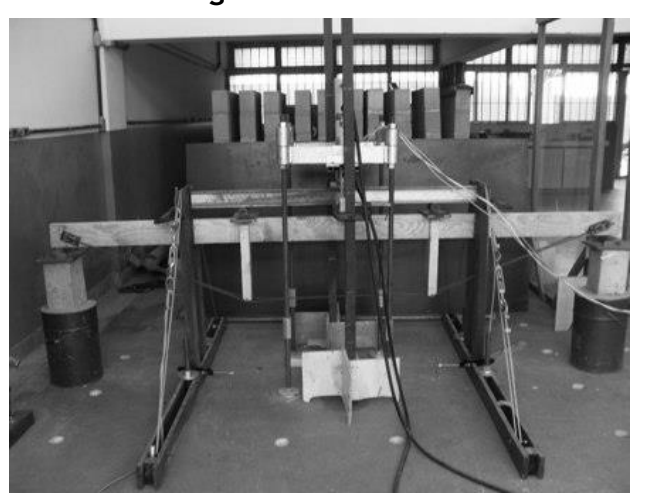

(a) Início do ensaio

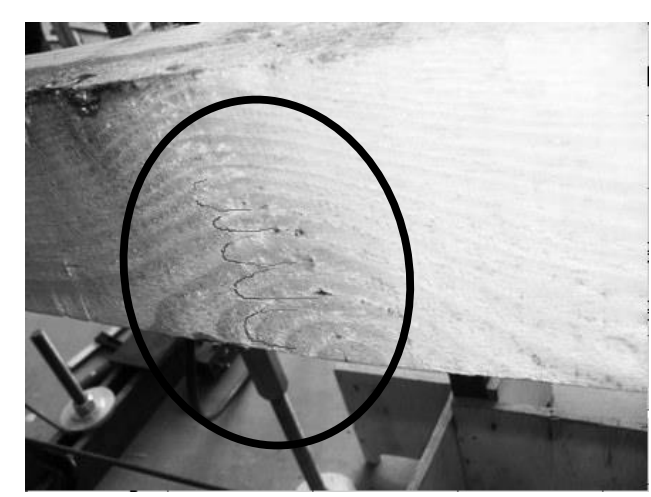

(b) Ruptura da viga

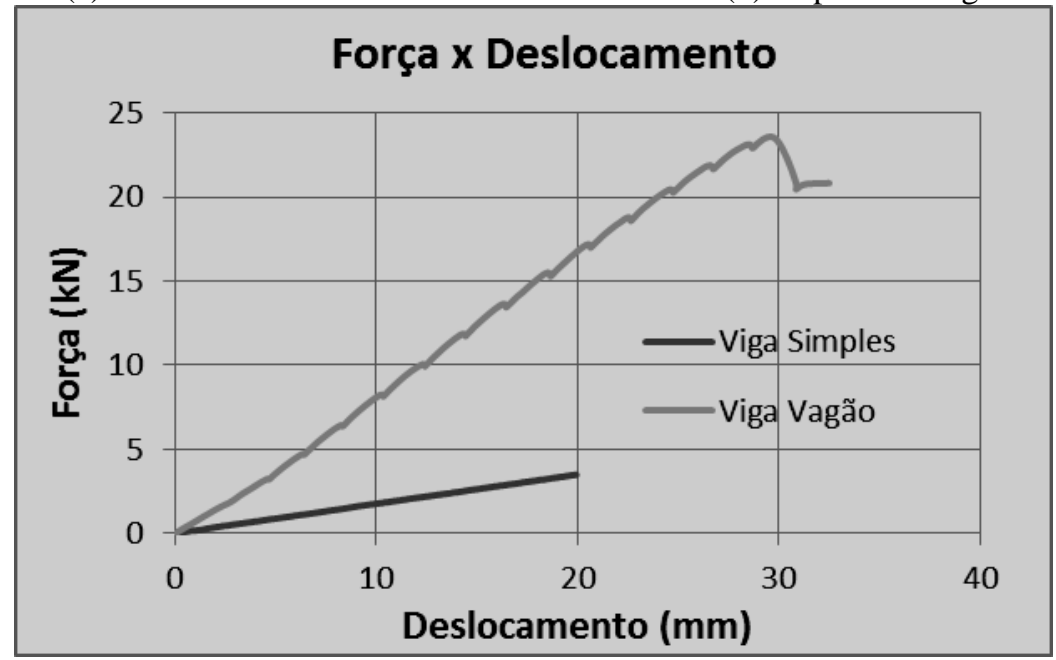

(c) Força $\times$ deslocamento da viga simples e viga vagão 
Figura 8 - Viga V5

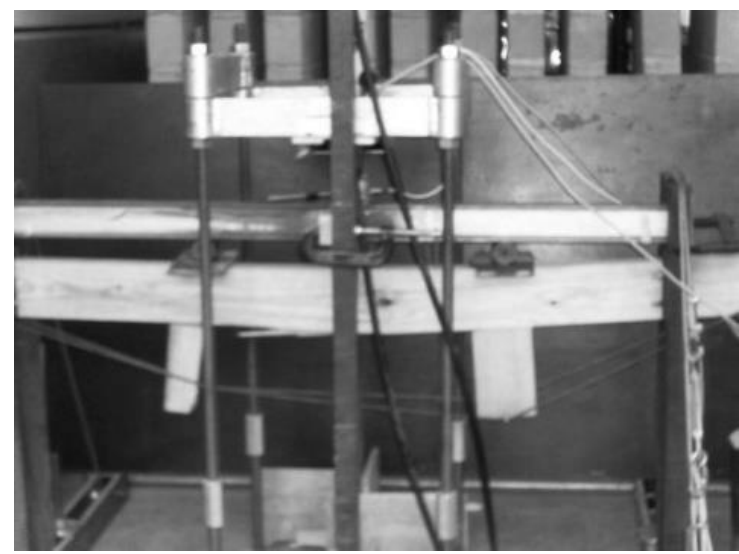

(a) Viga rompida

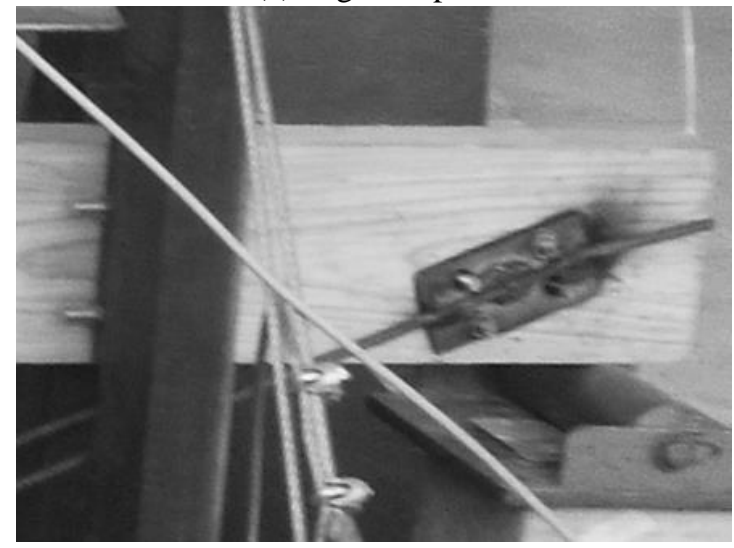

(c) Viga apoiada no início do ensaio

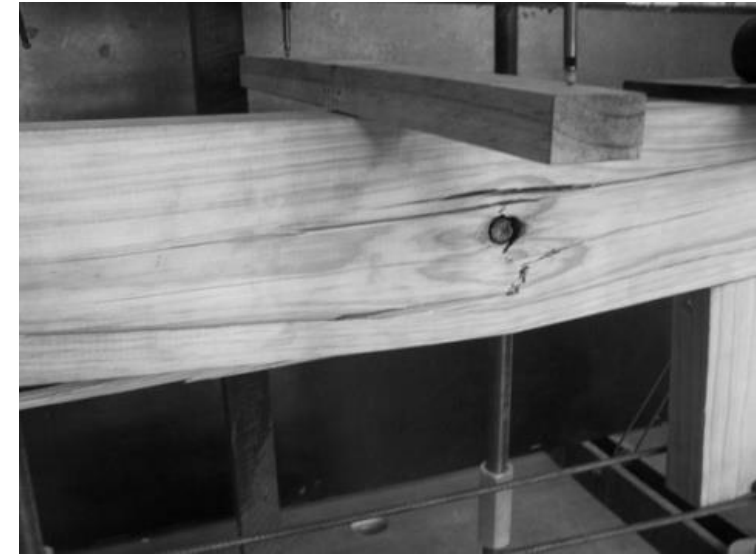

(b) Detalhe da seção rompida

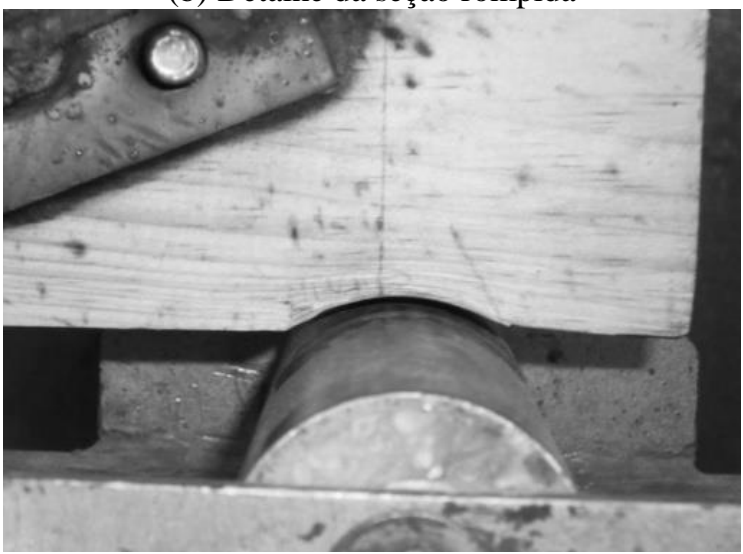

(d) Deformação da viga após o ensaio

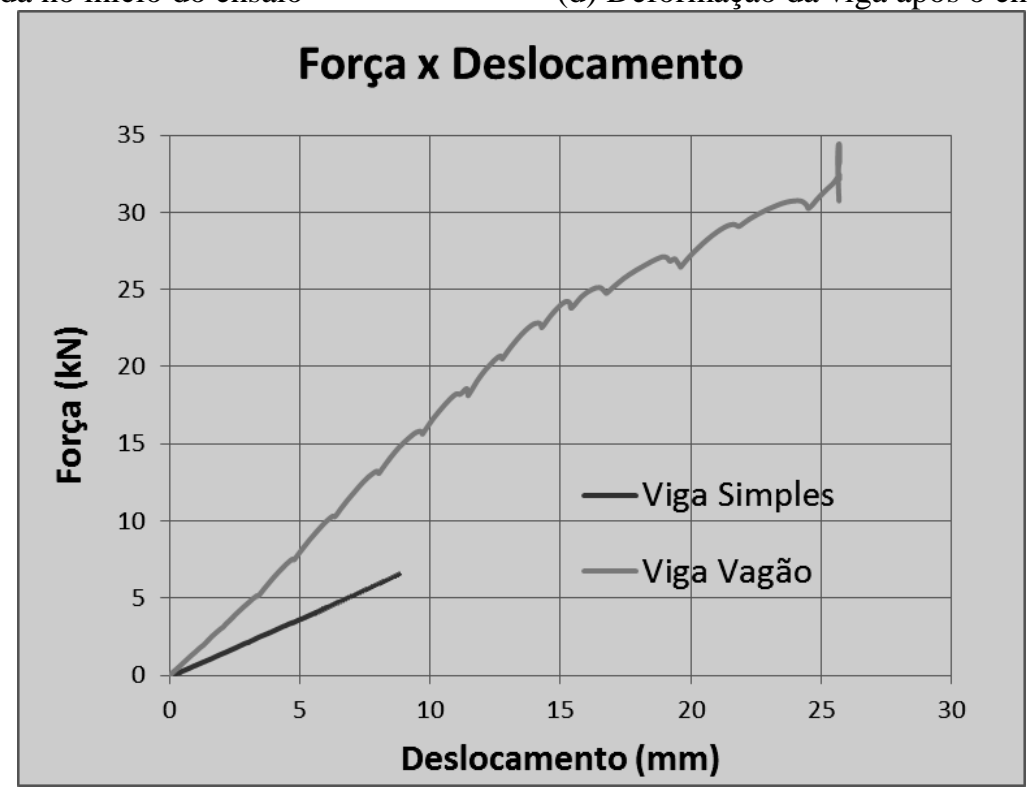

(e) Força $\times$ deslocamento da viga simples e da viga vagão 
Figura 9 - Ensaio da viga V6

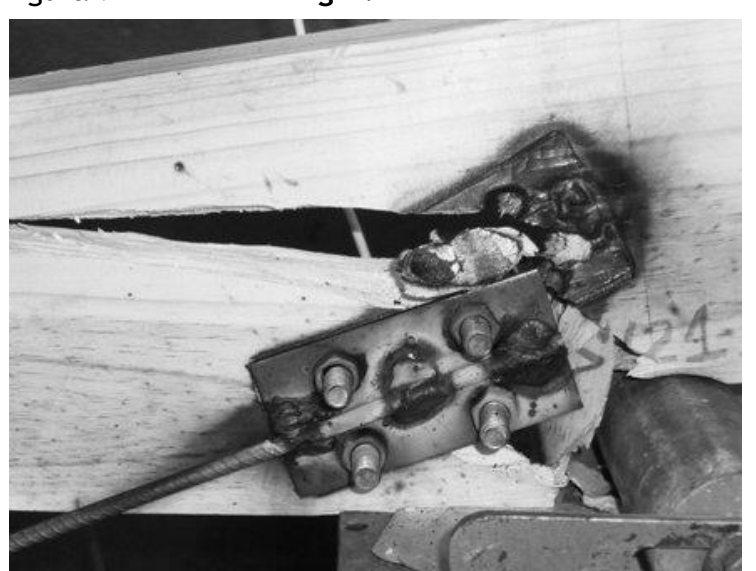

(a) Ruptura na região de fixação da chapa

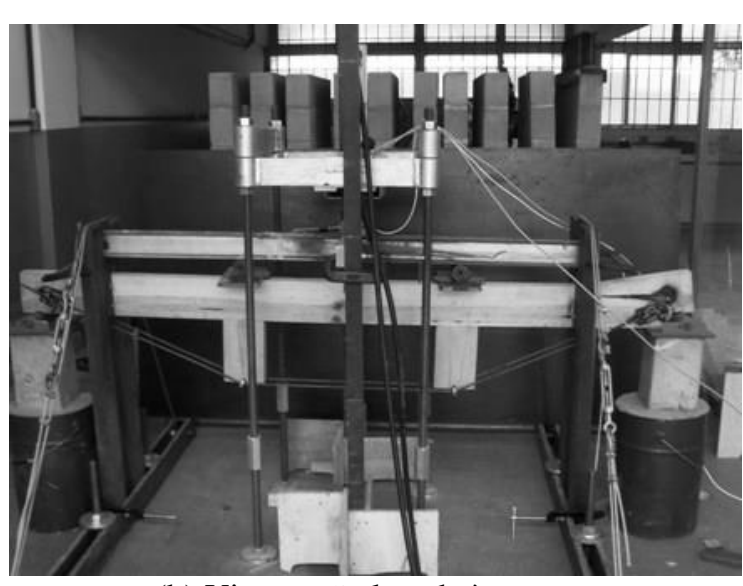

(b) Viga vagão levada à ruptura

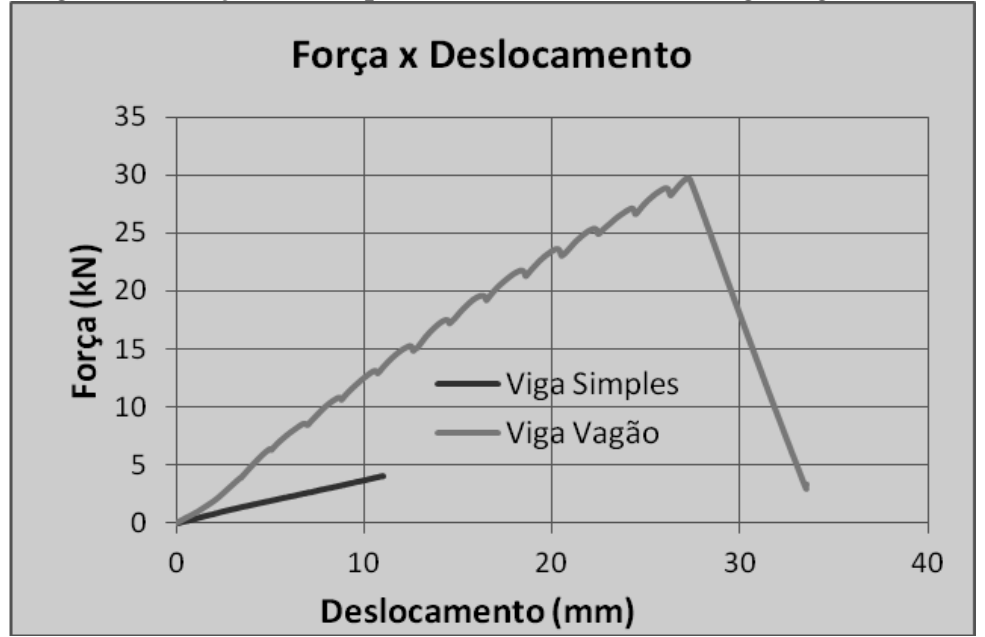

(c) Força $\times$ deslocamento da viga simples e da viga vagão

\section{Viga V7}

Foram montadas duas vigas de angelim vermelho, com vão livre de $290 \mathrm{~cm}$, para o ensaio com as barras de aço (vigas V7 e V8).

A viga $\mathrm{V} 7$, com seção transversal de $3,9 \mathrm{~cm} \times 9,3$ $\mathrm{cm}$, foi ensaiada primeiramente como viga simples, sendo carregada até $5 \mathrm{kN}$; em seguida o sistema foi descarregado, e foram acopladas as barras e chapas para o ensaio da viga vagão. Durante este segundo ensaio houve a ruptura de uma das barras de aço, próximo da região de solda (Figura 10).

Em análise superficial da peça de madeira, esta não estava danificada, portanto foram retiradas as chapas da viga e feito um novo ensaio da viga V7 simples, até a ruptura. No gráfico da Figura 11 nota-se que a viga simples rompeu com a aplicação de uma força de $10,34 \mathrm{kN}$; para esta mesma força o sistema viga vagão apenas apresentou um deslocamento vertical de $10 \mathrm{~mm}$.

\section{Viga V8}

A viga $\mathrm{V} 8$, com seção transversal de $3,8 \mathrm{~cm} \times 9,1$ $\mathrm{cm}$, assim como a V7, foi rompida como viga simples após falha no ensaio como viga vagão. No ensaio da viga vagão houve tombamento dos montantes, assim o ensaio foi paralisado com uma força de $31,86 \mathrm{kN}$. A deformação excessiva da barra impossibilitou a continuação do ensaio. Removidas as chapas com as barras, a viga foi ensaiada novamente, atingindo-se uma força de $14,9 \mathrm{kN}$ no momento em que rompeu. A Figura 12 ilustra aspectos da viga V8.

Na Figura 13 é mostrado o diagrama força $\times$ deslocamento do ensaio da viga V8 para os ensaios como viga simples e viga vagão.

\section{Análise experimental $\times$ análise numérica}

A fim de caracterizar e confirmar o comportamento do sistema, foram desenvolvidas 
duas análises numéricas, uma utilizando o software Ansys ${ }^{\circledR}$, que emprega o método dos elementos finitos, e outra utilizando o Gestrut (GESTRUT, 2010), que considera o sistema como reticulado, no caso plano. O Gestrut é um software acadêmico de fácil interface com o usuário, além de possuir um módulo especial para geração de dados para esse tipo de estrutura, em que é possível determinar os elementos como a viga, os montantes e o tirante, além de criar novas seções e informar dados como densidade e módulo de elasticidade.

Figura 10 - Ensaio da viga V7

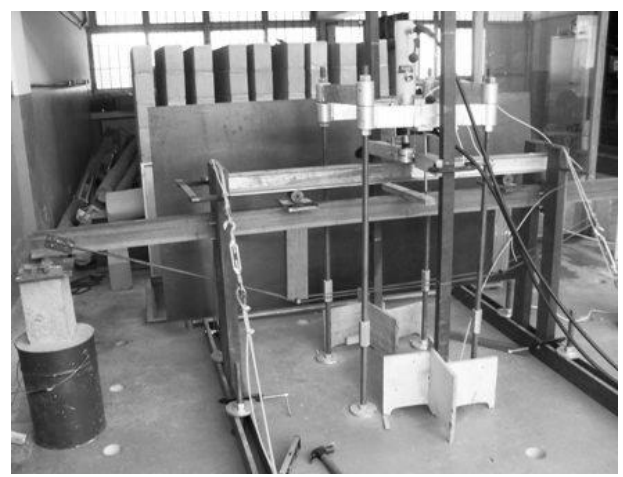

(a) Viga no início do ensaio
Foi realizada a análise numérica de cada peça, inserindo os dados reais como seção transversal, módulo de elasticidade, etc. Além disso, Gesualdo e Cunha (2009) apresentaram um estudo sobre a interferência da densidade da malha nos resultados de três parâmetros principais, tais como deslocamento, força no cabo e tensão normal. A Figura 14a ilustra o modelo geral de metade de uma viga vagão. A região do apoio do modelo numérico pode ser visualizada pela Figura 14b, e o detalhe da extremidade inferior do montante, com o pino transversal e o cabo, é mostrado na Figura $14 \mathrm{c}$.

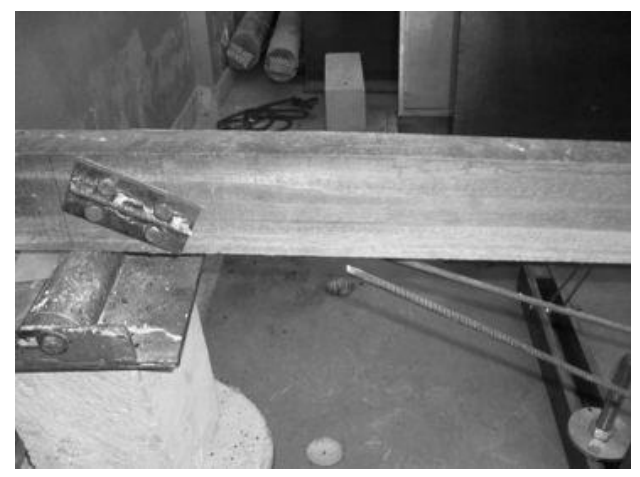

(b) Ruptura da barra de aço

Figura 11 - Representação gráfica do ensaio da viga V7

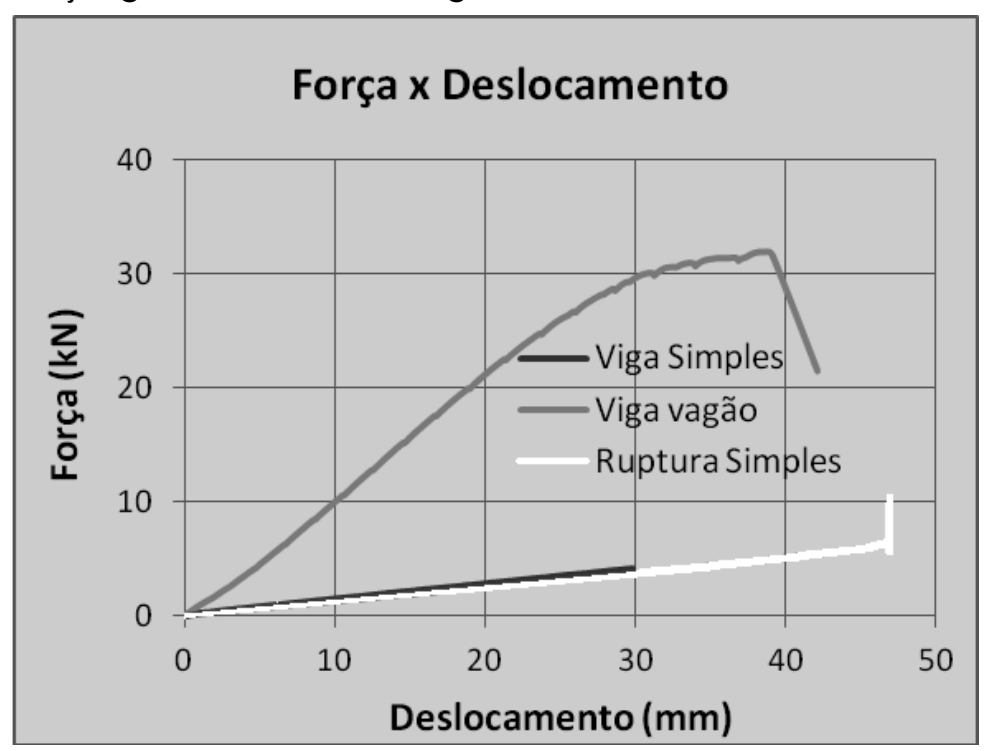


Figura 12 - Detalhes do ensaio da viga V8

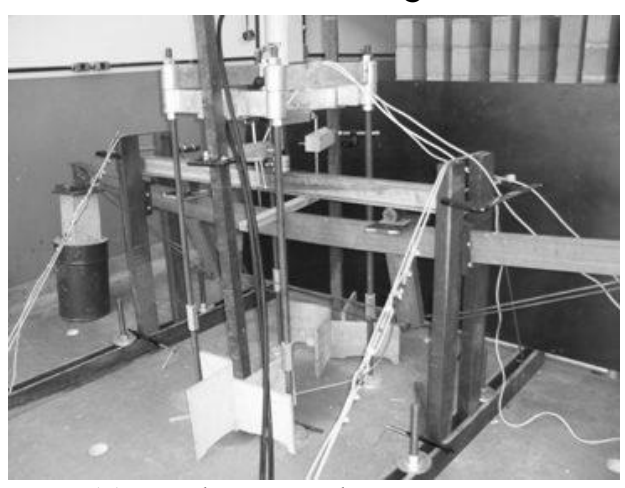

(a) Tombamento dos montantes

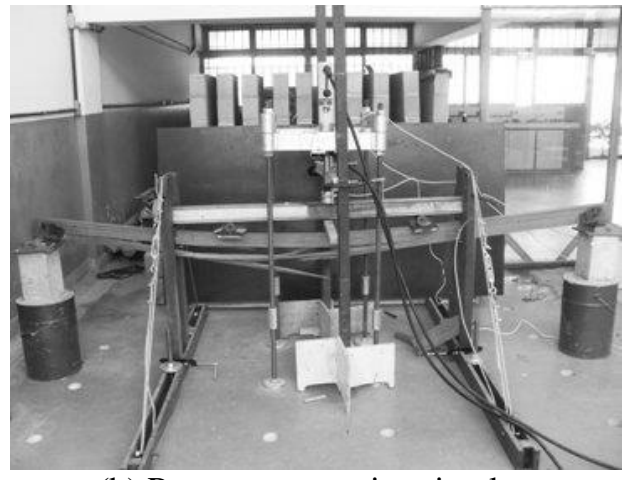

(b) Ruptura como viga simples

Figura 13 - Gráfico Força $\times$ Deslocamento da viga V8

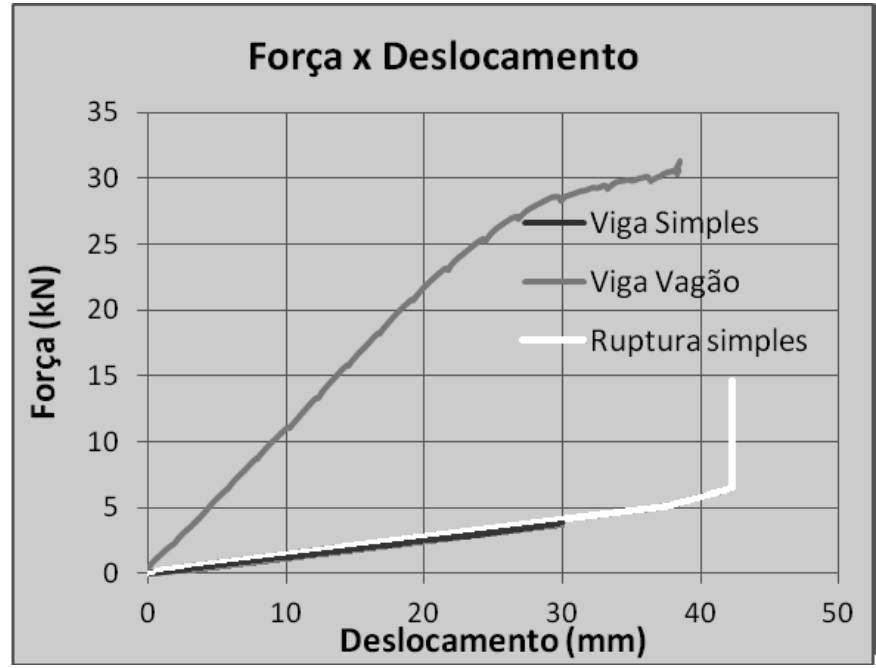

Figura 14 - Detalhes do modelo numérico

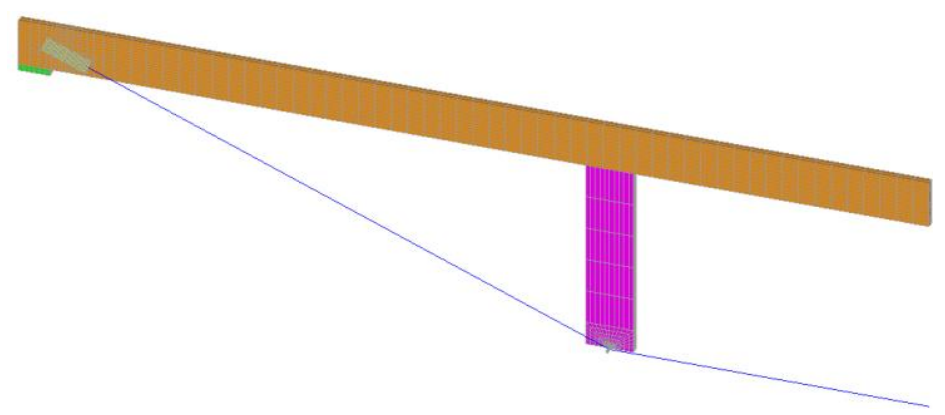

(a) Modelo de metade de uma viga vagão

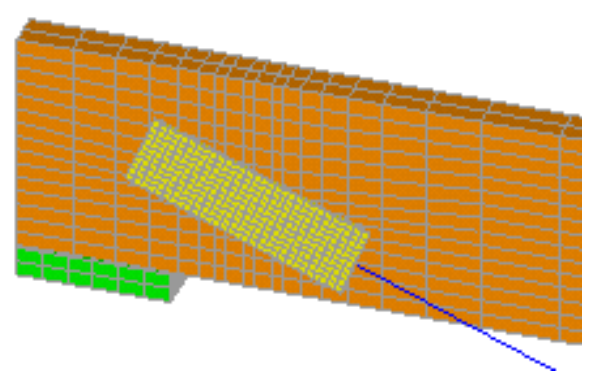

(b) Região do apoio

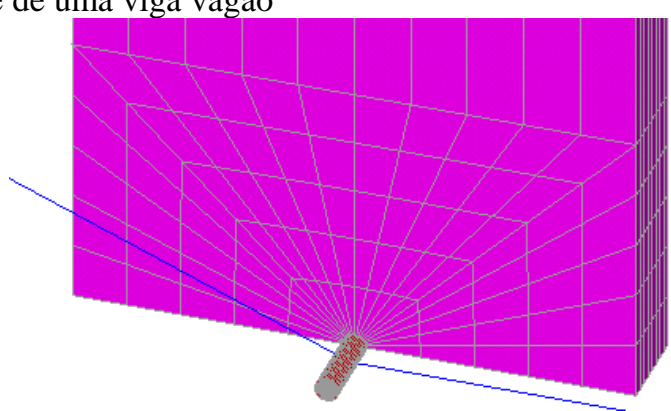

(c) Montante, pino transversal e cabo

238 Cunha, T. A.; Gesualdo, F. A. R. 
Figura 15 - Comparação entre modelos de cálculo para vigas com barra de aço Força $\times$ Deslocamento

Vigas com seção dupla de Pinus
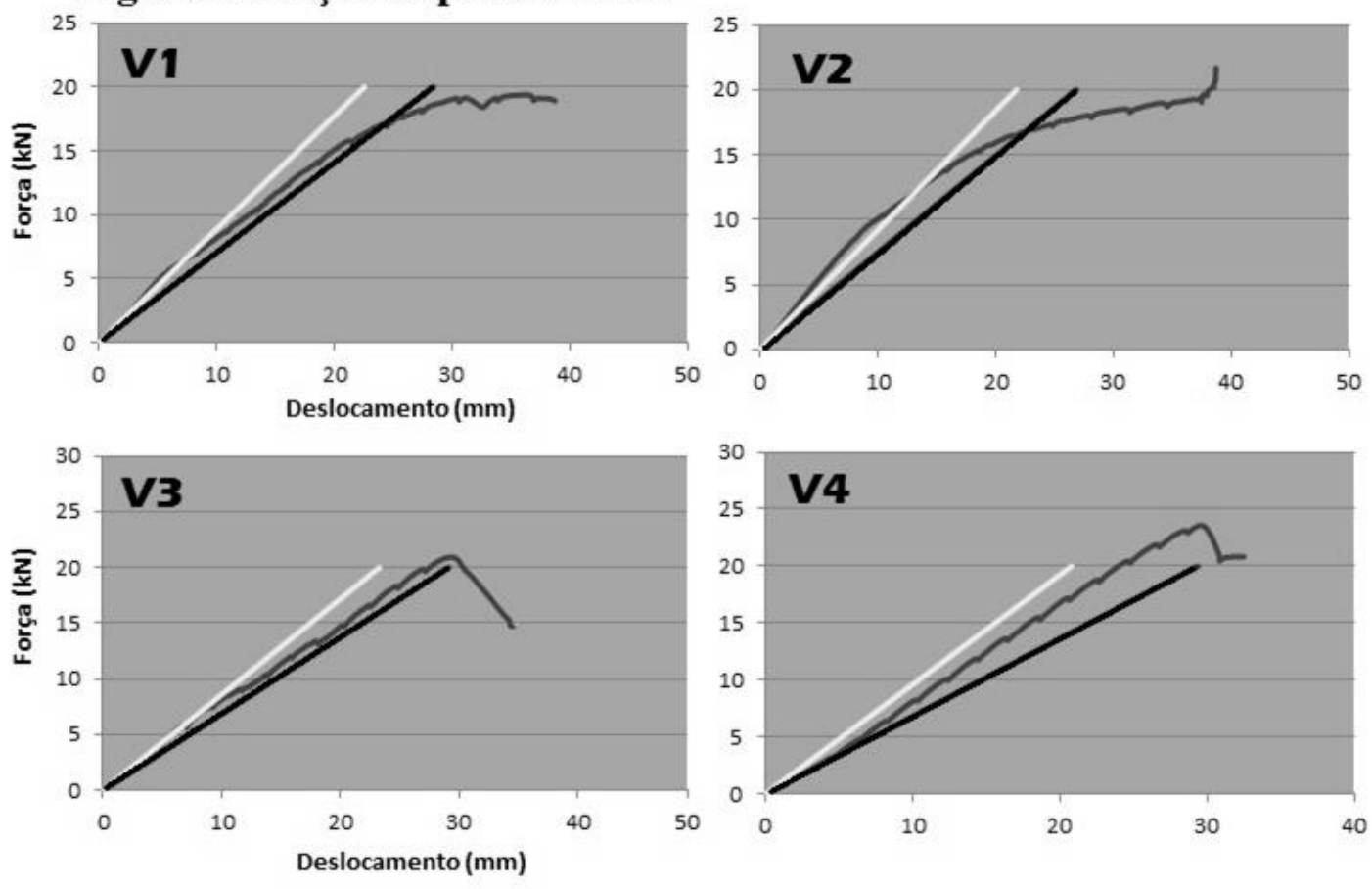

Vigas com seção maciça de Pinus
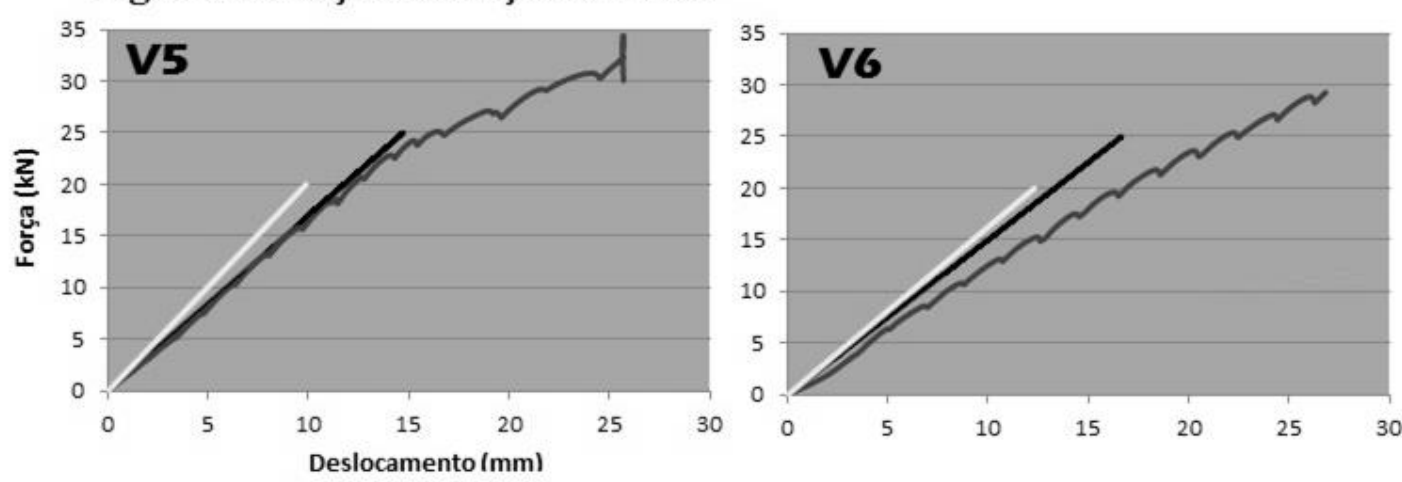

Vigas de Angelim Vermelho
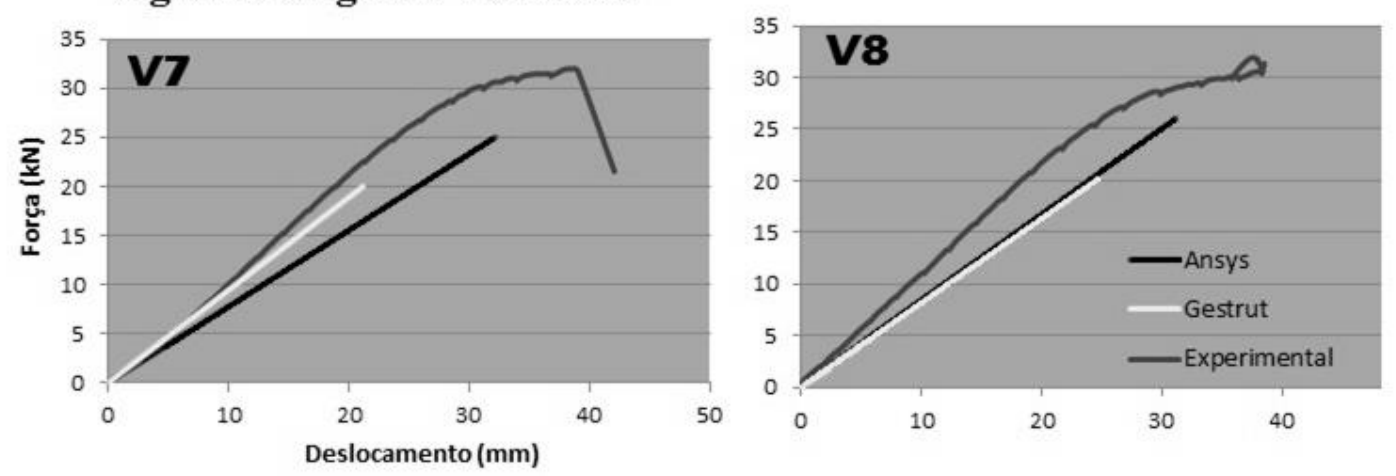
O objetivo do cálculo no Gestrut foi avaliar a eficiência - ou a possível perda de precisão quando se utiliza um modelo de cálculo mais simples, que não considera os detalhes de posicionamento de chapas, cabos, fixações, deformações localizadas, nem transferência de tensões por contato. Embora mais simples, é acessível à maioria dos projetistas. Os resultados comparativos estão representados na Figura 15.

Para geração do modelo completo pelo método dos elementos finitos é utilizado um programa computacional desenvolvido especialmente para a elaboração do código APDL (linguagem de comunicação do usuário com o Ansys ${ }^{\circledR}$ ) para vigas vagão de diferentes tipos. Este programa computacional tem o objetivo de facilitar a análise de diferentes tipos de viga vagão, pois é baseado na parametrização das informações, permitindo a rápida avaliação de vigas vagão com diferentes dimensões, sem a necessidade da enfadonha tarefa de geração do complexo modelo numérico.

As análises efetuadas e os gráficos mostrados validam o uso do modelo simplificado para dimensionamento da estrutura viga vagão. O cálculo utilizando o software Gestrut (modelo reticulado) foi satisfatório quando comparado com o Ansys e com o ocorrido em laboratório, independentemente do tipo de viga analisada (seção retangular maciça de pínus, angelim vermelho ou seção transversal dupla).

\section{Conclusões}

$\mathrm{Na}$ análise comparativa entre os sistemas viga simples e viga vagão comprovou-se a eficiência do sistema estudado, uma vez que, para as vigas de angelim vermelho, o ganho de rigidez foi de $623,01 \%$; para vigas com tábuas de pínus (vão livre de $290 \mathrm{~cm}$ ) o aumento foi de $517,71 \%$; e para as vigas maciças de pínus (vão livre de $210 \mathrm{~cm}$ ) o ganho de rigidez foi de $159,71 \%$, corroborando as informações encontradas na literatura.

Quanto ao sistema montado com tábuas de pínus, com seção transversal dupla, deve-se analisar melhor o método de fixação das tábuas para evitar que o esforço normal gerado pela barra de aço não seja fator limitante para a estabilidade do sistema. Há de ser observado que, mesmo com o surgimento da instabilidade, a resposta foi positiva, definindo-se a instabilidade como modo de ruptura. Da análise computacional feita para as quatro vigas montadas com tábuas de pínus, formando uma seção transversal dupla, três apresentaram boa aderência às curvas obtidas experimentalmente. As vigas de Angelim apresentaram leve divergência entre os modelos. Em contrapartida, para as duas vigas de pínus (V5 e V6) a curva experimental apresentou comportamento muito satisfatório, comparado com a curva gerada pelo modelo numérico. A comparação dos resultados obtidos experimentalmente com os dados do modelo simplificado e com os resultados do cálculo pelo método dos elementos finitos demonstrou que ambos são satisfatórios.

Em análises futuras complementares podem ser avaliados mais especificamente fatores associados às ligações, a fim de aperfeiçoar o modelo numérico e garantir mais facilidade na montagem do sistema.

\section{Referências}

ANSYS. Release 11.1 Documentation for ANSYS. SAS IP, Inc. Canonsburg, 2010.

FAHERTY, K. F.; WILLIAMSON, T. G. Wood Engineering and Construction. $3^{\text {th }}$. ed. Boston: McGraw Hill, 1999.

GESUALDO, F. A. R.; CUNHA, T.A. Two Wood Inverted Trussed Beams Using Transverse Steel

Pins Evaluated Via Finite Element Method Compared With Reticulated System. In: JORNADAS CHILENAS DE ESTRUCTURAS

DE MADERA; CONGRESO LATINO

AMERICANO DE ESTRUCTURAS DE

MADERA, 3., Concepcion, 2009. Anais...

Concepcion, 2009.

GESUALDO, F. A. R. ; LIMA, M. C. V. de. Análise Numérica de Viga Armada Formada por Postes Roliços de Eucalipto Com Cabo Metálico Enlaçado. In: CONGRESSO INTERNACIONAL EM MÉTODOS NUMÉRICOS EM ENGENHARIA; CONGRESSO LATINOAMERICANO SOBRE MÉTODOS COMPUTACIONAIS EM ENGENHARIA, Porto, 2007. Anais... Porto: Publindústria, 2007.

GESTRUT: Análise de estruturas tridimensionais reticuladas. Versão educacional. Uberlândia: Faculdade de Engenharia Civil da Universidade Federal de Uberlândia, 2010. Software. Disponível em: 〈http://www.feciv.ufu.br/node/135>. Acesso em: 26 nov. 2015.

HERZOG, T. et al. Timber Construction

Manual. Munich: Birkhauser, 2004.

JAMESON, C. D. The Evolution of the Modern Railway Bridge. Popular Science Monthly, Nova York, v. 36, p. 461-481, fev. 1980. 
MORAIS, T. M.; GESUALDO, F. A. R. Variação do Raio dos Pinos, do Comprimento e Posição dos Montantes em Vigas-Vagão de Eucalipto Feita Pelo Sistema de Enlaçamento de Cabos de Aço. In: ENCONTRO BRASILEIRO EM MADEIRAS E EM ESTRUTURAS DE MADEIRA, 11.,. Londrina, 2008. Anais... Londrina: UEL, 2008.

REBELLO Y. C. P.; BOGÉA V. M.

Geometria dos Elementos Estruturais: uma chave para a compreensão do comportamento estrutural. Integração, ABR. /MAI. /JUN. • $2004 \cdot$ Ano X, N $37 \cdot 127-136$.
RODRIGUES, R. M. S. C. O. Construções Antigas de Madeira: experiência de obra de reforço estrutural. Minho, 2004. 287 f. Dissertação (Mestrado em Engenharia Civil) - Escola de Engenharia, Universidade do Minho, Minho, 2004.

\section{Agradecimentos}

Os autores agradecem o incentivo e o apoio financeiro recebido da Fundação de Apoio à Pesquisa do Estado de Minas Gerais (Fapemig) para o desenvolvimento do tema relacionado a este trabalho.

\section{Revista Ambiente Construído}

Associação Nacional de Tecnologia do Ambiente Construído

Av. Osvaldo Aranha, $99-3^{\circ}$ andar, Centro

Porto Alegre - RS - Brasil

CEP $90035-190$

Telefone: +55 (51) 3308-4084

Fax: +55 (51) 3308-4054

www.seer.ufrgs.br/ambienteconstruido

E-mail: ambienteconstruido@ufrgs.br 